\title{
Development and Content Validation of the Psoriasis Symptoms and Impacts Measure (P-SIM) for Assessment of Plaque Psoriasis
}

\author{
Alice B. Gottlieb - Valerie Ciaravino - Christopher Cioffi • \\ Luke Peterson · Richard B. Warren
}

Received: July 10, 2020 / Published online: August 25, 2020

(C) The Author(s) 2020

\begin{abstract}
Introduction: Patients with plaque psoriasis experience a variety of signs and symptoms that can impact daily life, which may not be evaluated by clinician-reported outcomes. This study aimed to develop and assess the content validity of a new patient-reported outcome (PRO) measure to capture patient experiences of the signs, symptoms and impacts of psoriasis and aid integration of the patient perspective in treatment benefit-risk decision-making.
\end{abstract}

Digital Features To view digital features for this article go to https://doi.org/10.6084/m9.figshare.12758768.

Electronic supplementary material The online version of this article (https://doi.org/10.1007/s13555020-00434-3) contains supplementary material, which is available to authorized users.

A. B. Gottlieb

Icahn School of Medicine at Mount Sinai, New York, NY, USA

V. Ciaravino $(\bowtie)$

UCB Pharma, Brussels, Belgium

e-mail: valerie.ciaravino@ucb.com

C. Cioffi $\cdot$ L. Peterson

UCB Pharma, Raleigh, NC, USA

R. B. Warren

Dermatology Centre, Salford Royal NHS Foundation

Trust, Manchester NIHR Biomedical Research

Centre, The University of Manchester, Manchester, UK
Methods: The psoriasis symptoms and impacts measure (P-SIM) was developed based on a literature search and interviews with five clinical experts in psoriasis to identify frequent signs, symptoms and impacts of psoriasis. Hybrid concept elicitation, cognitive debriefing and usability testing interviews were conducted with moderate to severe psoriasis patients to evaluate the content validity and patient understanding of the preliminary P-SIM. The preliminary P-SIM was refined using initial quantitative analyses of phase $2 b$ data from psoriasis patients to inform the removal of any items.

Results: A preliminary 19-item P-SIM was developed for administration on a hand-held electronic tablet device using a 0-10 numerical response scale over a 24 -h recall period. Patient interviews and testing demonstrated most patients interpreted the items and responses as intended, would not re-word any items, felt the responses matched the items and rated the device as easy to use. After quantitative testing, five items were removed from the preliminary 19-item measure because of conceptual overlap, floor effects and/or skewed distributions to generate the final 14-item P-SIM.

Conclusions: The P-SIM questionnaire has good content validity; patients reported it was easy to understand and reflective of their experiences. Following psychometric validation, the P-SIM may be a useful PRO measure for capturing the signs, symptoms and impacts of 
psoriasis and may support clinician-reported outcomes when assessing treatment benefits in clinical trials.

Keywords: Bimekizumab; Content validation; Patient experience; Patient-reported outcomes; Plaque psoriasis; PRO development

\section{Key Summary Points}

\section{Why carry out this study?}

Patients with plaque psoriasis can be affected by a range of signs and symptoms that impact their daily life; however, these experiences are not captured by clinicianreported outcomes.

The objective of this study was to develop and validate the content of a new patient reported outcome (PRO) measure, the psoriasis symptoms and impacts measure (P-SIM), which aims to capture patient experience of the signs, symptoms and impacts of psoriasis.

\section{What was learned from the study?}

The P-SIM questionnaire has good content validity; patients found that the P-SIM was easy to understand and captured the key signs, symptoms and impacts they experience living with psoriasis.

Following psychometric validation, the P-SIM may be a useful PRO measure for understanding patients' experiences of psoriasis and could aid integration of the patient perspective in treatment benefitrisk decision-making.

\section{INTRODUCTION}

Plaque psoriasis is a chronic inflammatory skin disease $[1,2]$. Characterised by the presence of red and scaly plaques that may cause bleeding, itching and pain, the signs and symptoms of plaque psoriasis can negatively impact patient quality of life [2-4]. The impact of psoriasis on patient physical and psychological function has been reported to be comparable to that of other major medical conditions including cancer, arthritis, hypertension, heart disease, diabetes and depression [5]. Psoriasis disease burden is associated with the presence of comorbidities including psoriatic arthritis (PsA), which occurs in up to $30 \%$ of psoriasis patients [6].

In clinical trials for psoriasis treatments, efficacy is typically assessed using clinical outcome measures such as the Psoriasis Area and Severity Index (PASI) and the Investigator's Global Assessment (IGA). However, measuring the symptoms and effects of psoriasis on patients' daily lives is also key to understanding how to support their treatment needs and achieve effective disease management. Patientreported outcome (PRO) measures have been developed for the assessment of symptoms and functional impacts of psoriasis to support clinical measures. These include, but are not limited to, the psoriasis quality of life questionnaire (PQOL and PQOL-12) [7, 8], psoriasis symptom inventory electronic daily diary [9], psoriasis symptom diary $[10,11]$, psoriasis symptoms and signs diary [12] and the psoriasis symptom scale [13]. However, despite the number of currently available PRO instruments, none are freely available for use to capture psoriasis-specific signs, symptoms and impacts in the clinical evaluation of new treatments to support labeling claims. Therefore, a new PRO measure was developed specifically for use in the bimekizumab clinical trial programme with the aim of collecting data on patient experiences of living with psoriasis.

The psoriasis symptoms and impacts measure (P-SIM) has been developed to capture patients' experiences of key signs, symptoms and impacts of plaque psoriasis, with the intention to integrate the patient perspective into treatment benefit-risk decision-making. This article describes the iterative development process and evaluates the content validity of the P-SIM in patients with moderate to severe plaque psoriasis. 


\section{METHODS}

A review of the literature and interviews with clinical dermatologists were conducted to define the key signs, symptoms and impacts of plaque psoriasis and to generate proposed items for inclusion in the P-SIM. A preliminary questionnaire was developed, and patient interviews were used for concept elicitation, cognitive debriefing and usability testing of this initial version. Quantitative analysis and item finalisation of the P-SIM were conducted using phase $2 \mathrm{~b}$ clinical trial data.

\section{Literature Review}

A targeted literature review was performed between 11-16 February 2016 to identify the key signs, symptoms and impacts related to plaque psoriasis. Three academic literature databases were used as sources: MEDLINE, ProQuest Psychology and Academic Search Complete. Search terms applied to the title and abstract were "plaque psoriasis" and "sign OR symptom OR impact OR quality of life OR QoL OR activities of daily living (ADL) OR ADL OR focus group OR qualitative OR interview OR daily living OR ethnograph* OR patient perspective". No date filters were applied, although filters were applied for "human, adults and English" where possible. Title, abstract and fulltext reviews of the initial search results were performed to identify relevant articles for inclusion in the review. Studies that included a target population other than adults, or did not address signs, symptoms or impacts of plaque psoriasis, were excluded.

\section{Clinical Expert Interviews}

Five clinical dermatologists in the US, with expertise in managing adults with psoriasis, participated in semi-structured, one-to-one telephone interviews. Interviews were conducted from 7-10 March 2016 and lasted 60-75 min. All interviews were recorded, transcribed and thematically analysed. The main topics of the interviews included: a description of plaque psoriasis, diagnosis, key signs and symptoms, the burden of the disease and impacts on daily living and quality of life.

\section{Item Generation}

Nineteen items describing the signs, symptoms and impacts of plaque psoriasis were included in the preliminary version of the P-SIM. These were generated by a working group comprised of experts in PRO item generation, electronic clinical outcome assessment experts and team members from the UCB Pharma bimekizumab development team. The focus was on concepts mentioned most frequently in the clinical expert interviews. It was ensured that the items were: (1) adequately capturing the concepts identified from the literature review and clinical expert interviews; (2) clearly defined; (3) clinically relevant; (4) appropriate for use in the context of pivotal clinical trials for treatment of moderate to severe plaque psoriasis in adults.

\section{Patient Interviews}

\section{Patients}

Adults with moderate to severe plaque psoriasis (PASI $\geq 12, \geq 10 \%$ body surface area [BSA] affected by psoriasis and IGA score $\geq 3$ on a 5 -point scale) diagnosed for at least 6 months were recruited to participate in face-to-face hybrid concept elicitation, cognitive debriefing and usability testing interviews. Physicians and recruitment site staff were trained to screen and enroll patients from the 48-week extension phase (BE ABLE 2: NCT03010527) of a phase $2 \mathrm{~b}$ study in adults with moderate to severe plaque psoriasis (12-week phase 2b study: BE ABLE 1 [NCT02905006]). Its study design has been published previously $[14,15]$. To be included, patients: voluntarily provided written, informed consent; were able to speak, read, write and understand US English; were judged by the recruiting clinician to have adequate communication skills to share their experience with the disease. Patients were excluded from the study if they had: erythrodermic, guttate or generalised pustular forms of psoriasis or druginduced psoriasis; a history of chronic or recurrent infections, recent serious or life- 
threatening infection, or hospitalisation for any infection within the last 6 months; any current sign or symptom that may indicate an infection and may interfere with the their ability to report on their experience with psoriasis; a diagnosis of inflammatory conditions other than psoriasis or psoriatic arthritis; a history of chronic alcohol or drug abuse within the last 6 months. To recruit patients representative of the targeted population in the bimekizumab in plaque psoriasis clinical development programme, specific recruitment targets were employed: all patients should have diagnosis of moderate to severe plaque psoriasis; 3-5 could have psoriatic arthritis; all patients should have investigator global assessment (IGA) score of 3 (moderate) or 4 (severe).

\section{Interviews}

Mixed concept elicitation, cognitive debriefing and usability testing interviews were conducted based on a semi-structured interview guide. During concept elicitation, open-ended questions followed by probed questions were used to gain an understanding of plaque psoriasis signs, symptoms and impacts from the patient's perspective. Questions were non-leading, and targeted probes were only used after the initial open-ended questions to clarify concepts of interest. For concepts identified during the literature review and clinician interviews, patients were asked to rate how bothersome they found each concept on a numerical rating scale (NRS) from 0 (not bothersome)-10 (extremely bothersome). The severity of each sign and symptom reported by patients was also assessed on an NRS from 0 (no symptom)-10 (symptom as bad as you can imagine). During cognitive debriefing, patients' perceptions and interpretations of the preliminary 19-item P-SIM instructions, items and response options were captured. Finally, patients were asked to respond to structured rating questions related to the usability of the handheld electronic device used to complete the P-SIM and provide rationale for their ratings.

Each patient interview lasted $\sim 120 \mathrm{~min}$ and was audio-recorded. Recordings were transcribed verbatim and each transcript was analysed using a coding system applied to concepts reported spontaneously by patients, or as a result of further questioning from the interviewer, using ATLAS.ti version 7.5.10. The coding and analysis process was guided by established qualitative research methods, including grounded theory and constant comparative methods [16-18].

Interview data were assessed for conceptual saturation, which was considered to be achieved at the point when additional interviews would not yield new information. To evaluate conceptual saturation, concepts spontaneously emerging from the interviews were analysed in sets in the order the data were collected. Concepts reported in the first $25 \%$ of interviews were compared with the second $25 \%$ of interviews. Concepts reported in the first $50 \%$ of interviews were compared with the next $25 \%$ and, finally, concepts reported in the first $75 \%$ of interviews were compared with the last $25 \%$.

\section{Quantitative Analyses and Item Finalisation}

Quantitative analyses of the preliminary 19-item P-SIM were conducted using data from BE ABLE 1 [15].

A subset of randomised patients at study sites that elected to participate in the collection of PRO data completed the preliminary 19-item P-SIM daily over the 12-week study period from the baseline (week 0) visit. P-SIM data were collected at study visit weeks $0,1,2,4,6,8$ and 12. For each time point, except week 0 (these data were collected from a single assessment at the baseline study visit), a weekly score was calculated for each individual item as the mean of data from the seven days preceding the corresponding visit. Weekly scores were considered valid if at least four entries were completed during the preceding 7-day period. If $>3$ days were missing, then the weekly score was considered as missing. Only patients with at least one evaluable P-SIM weekly score were included in the analysis and there was no imputation of missing data.

Descriptive statistics (mean, median, standard deviation [SD], maximum value, minimum value and skewness) were calculated for 
the scores for each individual item of the preliminary 19-item P-SIM. Inter-item correlations, using Pearson's and Spearman's correlations, were calculated at weeks 0 and 1 .

\section{Compliance with Ethics Guidelines}

All patients gave informed consent. This study and the phase $2 \mathrm{~b}$ clinical trial (BE ABLE 1: NCT02905006), used for quantitative analysis, were conducted in accordance with the principles of the Declaration of Helsinki and the International Conference on Harmonization Guidance for Good Clinical Practice. Independent institutional review board and international ethics committee approvals were obtained from those listed in Supplementary Table S1, including the following central ethics committees and institutional review boards (IRB): Research Review Board Inc., Canada; Western IRB, USA; Copernicus Group IRB, USA; Komisja Bioetyczna przy Dolnoslaskiej Izbie Lekarskiej, Poland; Egeszsegugyi Tudomanyos Tanacs Klinikai Farmakologiai Eti, Hungary; FN Kralovske Vinohrady, Czech Republic.

\section{RESULTS}

\section{Literature Review}

The targeted literature review identified 286 publications, from which 24 articles were considered relevant for inclusion in the final review. The signs and symptoms covered by these articles were subdivided into two categories: (1) dermatologically observed skin changes and their sequalae and (2) physical discomfort. The most commonly reported observable dermatological signs and symptoms cited in the articles were erythaema (redness, skin irritation) and flaking (shedding, scaling of silvery white plaques and lesions). Other important but less commonly reported signs and symptoms were thickening of the skin, bleeding, cracking (tearing), soreness (tenderness) and dry skin. Physical discomfort signs and symptoms included burning sensation (stinging, tickling, crawling), pain (hurt, ache), soreness (tenderness), heat sensation, skin sensitivity, skin inflammation and swollen or stiff joints. In addition, pruritus (itch) was frequently reported as a physical discomfort sign and symptom (although this was sometimes referred to as an impact) detrimental to patients' health-related quality of life and functional ability. The impacts of plaque psoriasis most commonly identified from the literature search were the effects of the disease on social function (interference with interpersonal relationships, sexual difficulties/avoidance) and psychological function (including depression, anxiety, stress, distress, embarrassment). Other impacts included fatigue, sleep disturbance, limitations in exercise, limitations in daily activities, interference with work or studying, and influence on clothing choice.

\section{Clinical Expert Interviews}

The signs and symptoms of plaque psoriasis and impacts on patients described by clinical expert dermatologists were similar to those identified in the literature review. Clinicians described plaque psoriasis as a visible chronic skin condition caused by a dysfunction in the immune system, commonly characterised by skin redness, scaling, flaking, bleeding, itching and pain. All five clinicians reported redness, itching and scaling, whilst $4 / 5$ reported flaking, bleeding and pain. Other signs and symptoms described by at least $2 / 5$ clinicians were skin irritation, fatigue, skin thickness, stinging, cracking, soreness, lesions and plaques. Depression, interference with relationships and limitation of exercise or activities were the impacts most commonly mentioned by clinicians $(5 / 5)$. Other impacts reported included shame/embarrassment, fatigue, interference with work or study and sleep disturbance. In addition, clinicians noted that the appearance of plaque psoriasis was often a burden on patients, especially regarding how they felt about themselves and their appearance. Itch was reported to have a high burden on patients. 


\section{Item Generation for the Preliminary 19-Item P-SIM}

Using concepts arising from the targeted literature review and the clinical expert interviews, a preliminary version of the P-SIM was generated, with 19 items covering frequently reported signs, symptoms and impacts of plaque psoriasis. The P-SIM was designed to be completed daily using a handheld electronic tablet device to assess the patient experience of the concept in each item over the past $24 \mathrm{~h}$ using an 11-point NRS. A score of 0 indicates an experience of no sign, symptom or impact, whereas a score of 10 indicates an experience of a very severe sign, symptom or impact. The instructions for the P-SIM, a list of the 19 questions and their responses can be found in Table 1.

\section{Patient interviews}

\section{Patients}

A total of 15 patients, based in the US, with moderate to severe plaque psoriasis participated in the interviews; $2 / 15$ (13.3\%) also had PsA. The majority of patients were male $(n=9$, $60.0 \%)$, were white $(n=11,73.3 \%)$ and reported 'very good' or 'good' health status (Table 2). Patients had a mean age of 51.1 years $(\mathrm{SD}=$ 13.8; Table 2).

\section{Concept Elicitation}

Signs, Symptoms and Impacts A total of 59 signs, symptoms and impacts of plaque psoriasis were reported by patients during the interviews. Table 3 provides a summary of the frequency of reporting, bothersome ratings and severity ratings for signs, symptoms and impacts included in the preliminary 19-item P-SIM; example quotes from patients discussing these items are in Table 4. Complete data for all signs, symptoms and impacts reported during concept elicitation can be found in Supplementary Tables S2-4.

Amongst the most commonly reported signs, symptoms and impacts, skin itching and redness (Table 3), along with skin damage caused by scratching or picking at the skin (Supplementary Table S2), were spontaneously reported by all patients. Scaling, flaking, dryness and impact on clothing choice were also reported by all patients, either spontaneously or upon probing by the interviewer (Table 3 ).

Itch was the most frequently rated on both the bothersome $(n=15 / 15,100.0 \%)$ and severity scales $(n=12 / 15,80.0 \%)$, receiving mean scores of $7.7 / 10$ and $8.3 / 10$, respectively (Table 3). Other signs, symptoms and impacts rated most frequently on the bothersome scale were impact on clothing choice $(n=14 / 15$, 93.3\%; mean 6.3/10), redness $(n=13 / 15$, $86.7 \%$; mean $8.2 / 10)$, dryness $(n=12 / 15$, $80.0 \%$; mean $7.7 / 10)$ and flaking $(n=12 / 15$, 80.0\%; mean 8.2/10). Redness and flaking were also frequently rated for severity (both $n=9 / 15$, $60.0 \%$; mean 5.9/10 and 7.8/10, respectively). Scaling was rated by $66.7 \%$ of patients on the bothersome scale and pain rated by $53.3 \%$ of patients (Table 3 ). Both were considered bothersome by patients and received mean scores of $8.1 / 10$ and $7.5 / 10$, respectively (Table 3 ).

Saturation Qualitative data from the concept elicitation interviews were also assessed for conceptual saturation. There were 28 spontaneously reported signs and symptoms of plaque psoriasis over the course of the 15 patient interviews. Over $75 \%$ of these signs and symptoms were reported during the first three interviews, and nearly $90 \%$ were reported by the fourth interview. All signs and symptoms were reported by the sixth interview and no new spontaneously reported signs or symptoms emerged after this point. Nearly $70 \%$ of the 30 spontaneously reported impacts were reported by the third interview and nearly $90 \%$ were reported by the sixth interview. All impacts were reported by the eleventh interview, with no new spontaneously reported impacts reported during the remaining interviews. This suggests that sign, symptom and impact conceptual saturation was achieved, negating the need for any further interviews.

\section{Cognitive Debriefing}

Item Feedback All patients ( $n=15 / 15$, $100.0 \%)$ interpreted the instructions as intended and reported that they would not re-word the instructions (Table 5). More than half of 
Table 1 Preliminary 19-item P-SIM

\begin{tabular}{ll}
\hline Item & Response scale \\
\hline
\end{tabular}

Instructions: The following questions refer to things that you may experience as a result of your psoriasis. Please read through and complete the questions on the following screens. There are no right or wrong answers. Please select the answer that best applies to you as a result of your psoriasis

1. During the past $24 \mathrm{~h}$, how severe was your worst skin itching?

2. During the past $24 \mathrm{~h}$, how severe was your worst skin redness?

3.During the past $24 \mathrm{~h}$, how severe was your worst skin pain?

4. During the past $24 \mathrm{~h}$, how severe was your worst skin burning?

5. During the past $24 \mathrm{~h}$, how severe was your worst skin scaling?

6. During the past $24 \mathrm{~h}$, how severe was your worst skin stinging?

7. During the past $24 \mathrm{~h}$, how severe was your worst skin cracking?

8. During the past $24 \mathrm{~h}$, how severe was your worst skin flaking?

9. During the past $24 \mathrm{~h}$, how severe was your worst skin dryness?

10. During the past $24 \mathrm{~h}$, how severe was your worst skin irritation?

11. During the past $24 \mathrm{~h}$, how severe was your worst skin sensitivity?

12. During the past $24 \mathrm{~h}$, how severe was your worst skin lesions (red marks, spots, or inflammation)?

13. During the past $24 \mathrm{~h}$, how severe was your worst skin thickening (hardening or roughening)?

14. During the past $24 \mathrm{~h}$, how severe was your itch-related sleep loss?

15. During the past $24 \mathrm{~h}$, at its worst, how severe was your psoriasisrelated fatigue (weariness, tiredness)?

16. During the past $24 \mathrm{~h}$, at its worst, how much embarrassment did you feel as a result of your psoriasis?

17. During the past $24 \mathrm{~h}$, at its worst, how much did you avoid doing your usual activities as a result of your psoriasis?

18. During the past $24 \mathrm{~h}$, at its worst, how much did your psoriasis impact your personal relationships (e.g., with family, friends, or work colleagues)?

19. During the past $24 \mathrm{~h}$, at its worst, how much did your psoriasis impact your choice of clothing?
0 (No itching)-10 (very severe itching)

0 (No skin redness)-10 (very severe skin redness)

0 (No skin pain)-10 (very severe skin pain)

0 (No skin burning)-10 (very severe skin burning)

0 (No skin scaling)-10 (very severe skin scaling)

0 (No skin stinging)-10 (very severe skin stinging)

0 (No skin cracking)-10 (very severe skin cracking)

0 (No skin flaking)-10 (very severe skin flaking)

0 (No skin dryness)-10 (very severe skin dryness)

0 (No skin irritation)-10 (very severe skin irritation)

0 (No skin sensitivity)-10 (very severe skin sensitivity)

0 (No skin lesions)-10 (very severe skin lesions)

0 (No skin thickening)-10 (very severe skin thickening)

0 (No itch-related sleep loss)-10 (Worst possible itchrelated sleep loss)

0 (No fatigue)-10 (worst possible fatigue)

0 (No feelings of embarrassment)-10 (worst possible feelings of embarrassment)

0 (No avoidance of my usual activities) -10 (completely avoided doing my usual activities)

0 (No impact on personal relationships)-10 (completely impacted personal relationships)

0 (No impact on my choice of clothing)-10 (completely impacted my choice of clothing)

Items in italics were removed from the final P-SIM questionnaire because of quantitative analysis results $P$-SIM psoriasis symptoms and impacts measure 
Table 2 Patient interview demographics and characteristics

\begin{tabular}{|c|c|}
\hline Characteristic & Total patients $(N=15)$ \\
\hline \multicolumn{2}{|l|}{ Age, years } \\
\hline Range & $24-77$ \\
\hline Average (SD) & $51.1(13.8)$ \\
\hline \multicolumn{2}{|l|}{ Gender, $n(\%)$} \\
\hline Male & $9(60.0)$ \\
\hline Female & $6(40.0)$ \\
\hline \multicolumn{2}{|l|}{ Race, $n$ (\%) } \\
\hline White & $11(73.3)$ \\
\hline Asian & $4(26.7)$ \\
\hline \multicolumn{2}{|l|}{ Work status, $n(\%)$} \\
\hline Working full time & $10(66.7)$ \\
\hline Working part time & $1(6.7)$ \\
\hline Retired & $2(13.3)$ \\
\hline Homemaker & $1(6.7)$ \\
\hline Unemployed & $1(6.7)$ \\
\hline \multicolumn{2}{|c|}{ General health status, $n(\%)$} \\
\hline Excellent & $2(13.3)$ \\
\hline Very good & $6(40.0)$ \\
\hline Good & $6(40.0)$ \\
\hline Fair & $1(6.7)$ \\
\hline
\end{tabular}

$S D$ standard deviation

patients with evaluable data (>57\%) interpreted all items as intended and most patients with evaluable data (>58\%) reported that they would not re-word any of the items (Table 5). Skin itching, pain and scaling items from the P-SIM were used as secondary end points in phase 3 clinical trials. Out of these items most patients interpreted itching and pain as intended $(n=15 / 15,100.0 \%$ and $n=13 / 15,86.7 \%$, respectively; (Table 5); $60.0 \% \quad(n=9 / 15)$ of patients interpreted the scaling item as intended (Table 5); most patients who misinterpreted the item did so because they interpreted the item to be the same as skin flaking. In addition, $>75 \%$ of patients with evaluable data reported that they would not re-word the itching, pain or scaling items.

Response options for all the P-SIM items were interpreted as intended by $>80 \%$ of patients with evaluable data (Table 6). Most patients with evaluable data $(>80 \%)$ also felt that the response scale matched the question for each item (Table 6). The response options for itch, pain and scaling were interpreted by $100.0 \%, 85.7 \%$ and $100.0 \%$ of patients with evaluable data, respectively (Table 6), and most (>89\%) said that the response scale matched the questions for these items.

General Feedback When asked about their general impressions of the preliminary 19-item P-SIM, most patients reported that there were no words that were difficult to understand $(n=9 / 15,60.0 \%)$, no concepts missing $(n=11 /$ $15,73.3 \%)$ and no items were redundant $(n=8 /$ $15,53.3 \%)$.

Recall Period The P-SIM was designed to be completed daily and requires patients to rate the severity of each item during the past $24 \mathrm{~h}$. When providing feedback during the patient interviews, most patients interpreted the 24-h recall period as intended $(n=11 / 15,73.3 \%)$. Four patients had an issue adhering to the recall period and instead used a different recall period (e.g., "in general, every day" [1-12]).

\section{Usability Testing}

Overall, patients found the electronic tablet device used to complete the preliminary 19-item P-SIM easy to use. On a scale of 1 (poor)-5 (excellent), most patients rated the device as "excellent" for finger sensitivity, stylus sensitivity and overall appearance $(n=10 / 15$, $66.7 \% ; n=13 / 15,86.7 \% ; n=11 / 15,73.3 \%$, respectively; Supplementary Table S5). On a similar scale of 1 (difficult)-5 (easy), most patients rated selecting an answer, advancing to the next screen, readability of font size and overall ease of use of the device as "easy" $(n=13 / 15,86.7 \% ; \mathrm{n}=14 / 15,93.3 \% ; \mathrm{n}=10 / 15$, $66.7 \% ; n=13 / 15,86.7 \%$, respectively; Supplementary Table S5). 
Table 3 Summary of patient feedback on items from the preliminary P-SIM $(N=15)$

\begin{tabular}{|c|c|c|c|c|c|}
\hline \multirow{2}{*}{$\begin{array}{l}\text { Concept (worst } \\
\text { severity in P-SIM) }\end{array}$} & \multirow{2}{*}{$\begin{array}{l}\text { Frequency of report during } \\
\text { concept elicitation, } n(\%)\end{array}$} & \multicolumn{2}{|c|}{ Bothersome rating $^{a}$} & \multicolumn{2}{|c|}{ Severity rating $^{\mathbf{b}}$} \\
\hline & & $\begin{array}{l}\text { Frequency }{ }^{\mathrm{c}}, \\
n(\%)\end{array}$ & $\begin{array}{l}\text { Average, } \\
\text { mean }(S D)\end{array}$ & $\begin{array}{l}\text { Frequency, } \\
n(\%)\end{array}$ & $\begin{array}{l}\text { Average, } \\
\text { mean }(S D)\end{array}$ \\
\hline 1. Skin itching & $15(100.0)$ & $15(100.0)$ & $7.7(2.8)$ & $12(80.0)$ & $8.3(3.8)$ \\
\hline 2. Skin redness & $15(100.0)$ & $13(86.7)$ & $8.2(3.4)$ & $9(60.0)$ & $5.9(3.4)$ \\
\hline 3. Skin pain & $8(53.3)$ & $8(53.3)$ & $7.5(4.3)$ & $7(46.7)$ & $7.3(4.1)$ \\
\hline 4. Skin burning & $6(40.0)$ & $4(26.7)$ & $8.5(3.9)$ & $2(13.3)$ & $9.0(3.2)$ \\
\hline 5. Skin scaling & $15(100.0)$ & $10(66.7)$ & $8.1(4.3)$ & $5(33.3)$ & $6.6(3.5)$ \\
\hline 6. Skin stinging ${ }^{\mathrm{d}}$ & $7(46.7)$ & $1(6.7)$ & $8.0(2.1)$ & $1(6.7)$ & $8.0(2.1)$ \\
\hline 7. Skin cracking & $12(80.0)$ & $10(66.7)$ & $7.5(4.4)$ & $6(40.0)$ & $6.5(3.7)$ \\
\hline 8. Skin flaking ${ }^{\mathrm{d}}$ & $15(100.0)$ & $12(80.0)$ & $8.2(3.9)$ & $9(60.0)$ & $7.8(4.2)$ \\
\hline 9. Skin dryness & $15(100.0)$ & $12(80.0)$ & $7.7(3.7)$ & $7(46.7)$ & $7.4(4.1)$ \\
\hline 10. Skin irritation & $11(73.3)$ & $7(46.7)$ & $7.0(3.9)$ & $6(40.0)$ & $6.8(3.9)$ \\
\hline 11. Skin sensitivity & $5(33.3)$ & $5(33.3)$ & $8.0(4.0)$ & $2(13.3)$ & $7.0(2.5)$ \\
\hline 12. Skin lesions & $8(53.3)$ & $1(6.7)$ & $9.0(2.3)$ & $1(6.7)$ & $2.0(0.5)$ \\
\hline 13. Skin thickening & $12(80.0)$ & $6(40.0)$ & $6.7(3.8)$ & $4(26.7)$ & $6.8(3.1)$ \\
\hline 14. Sleep loss ${ }^{\mathrm{d}}$ & $12(80.0)$ & $8(53.3)$ & $7.1(4.2)$ & - & - \\
\hline 15. Fatigue & $2(13.3)$ & $1(6.7)$ & $8.0(2.0)$ & - & - \\
\hline $\begin{array}{l}\text { 16. Feelings of } \\
\text { embarrassment }\end{array}$ & $7(46.7)$ & $3(20.0)$ & $7.0(2.9)$ & - & - \\
\hline $\begin{array}{l}\text { 17. Avoid doing usual } \\
\text { activities }^{\mathrm{d}}\end{array}$ & $9(60.0)$ & $4(26.7)$ & $5.0(2.9)$ & - & - \\
\hline $\begin{array}{l}\text { 18. Personal } \\
\text { relationships }^{\mathrm{d}}\end{array}$ & $11(73.3)$ & $7(46.7)$ & $6.4(3.9)$ & - & - \\
\hline 19. Choice of clothing & $15(100.0)$ & $14(93.3)$ & $6.3(3.0)$ & - & - \\
\hline
\end{tabular}

P-SIM psoriasis symptoms and impacts measure, SD standard deviation

a On a scale of 0 to 10 , where $0=$ not bothersome at all and $10=$ extremely bothersome

b On a scale of 0 to 10 , where $0=$ no $[\mathrm{sign} /$ symptom $]$ and $10=[\mathrm{sign} /$ symptom $]$ as bad as you can imagine

c In some cases, the $N$ providing a bothersome/severity rating does not equal the total number of patients reporting this concept. These instances occurred because (1) the patient was not asked to provide a rating because of time constraints and/ or interviewer's discretion or (2) the patient's response was found to be inconclusive during analysis

$\mathrm{d}$ This item was ultimately removed from the final 14-item P-SIM

\section{Quantitative Analyses and Item Finalisation}

A total of 180 patients from the phase $2 \mathrm{~b}$ BE ABLE 1 study had evaluable P-SIM data at any time point. These patients were recruited from study sites in Canada $(n=39,21.7 \%)$, Poland $(n=114,63.3 \%)$ and the USA $(n=27,15.0 \%)$. The mean age was $43.4(\mathrm{SD}=13.6), 67.2 \%$ $(n=121)$ were male and 93.3\% $(n=168)$ were white (Supplementary Table S6). At week 0 the mean PASI score was $18.7(S D=5.9)$. To inform 
Table 4 Concept elicitation results: example patient quotes on concepts in the preliminary 19-item P-SIM

\section{Item Example quotes}

1. Skin itching [01-04]: ...like you've been, you know, rolling around in the grass, and you got a million little grass cuts and you're all itchy. It's like that...In fact you feel itchy over your entire body even where there's not psoriasis for some reason. ...it's gotta be part of the psoriasis you know

2. Skin redness [01-02]: ...it's kind of like poison ivy, sort of, because um, the area that's already like slightly pink will get more red and then you just got, you just want to scratch it. ...pink when it's sometimes controlled. Red when it, it's like really irritating

3. Skin pain [01-04]: I mean, well I mean it can feel pain like a real a soreness or something. You can feel the, the scales like pushing together or something like that, you know

4. Skin burning [01-05]: At its absolute worst as far as feeling goes, it gets to the point where it feels hot or itchy and I have a nature of, even if I know I'm not supposed to scratch it really bad...And then it, it gets painful, um, and not always, but most of the time gets painful and like um, almost like a heat pain...The heat pain for me is basically that it, it's, I feel pain but I also feel hot in the area...

5. Skin scaling [01-15]: Scales are messy. They show up everywhere. You can just be walking and you know, you just scratch it like a little bit and then, you know, and it falls out...my legs have always been the worst, so it just does doesn't go away so it's always scaling

6. Skin [01-02]: It will sting at first but then you'll see the red. It will bleed a tiny bit and then you have to, the stinging um, white coating from the body coming out to try to heal the wound, which is still the actual psoriasis itself also works out that way because it pushes double the amount...It stings once it hits the air the first time, like a regular wound

7. Skin [01-09]: I feel like it looks like cracked um, I don't know if scaly is the right word. It's more like, like, it's cracking almost like cracked skin like if, if, if you ever had your knuckles get really really dried out in the winter so bad. Or from like washing a lot of dishes, I can only compare it to that where you get like these little cracks that sort of go through all that and it's like into the red part. More like a cracking. Thin, thin small cracks

8. Skin flaking ${ }^{a}$ [01-04]: ...I'll sweep the floor in my room and there'll be a big pile of skin flakes...Um, like I say, when I, when it's really bad, it's you know you'll get like the, the plates, can be like two inches in diameter, something like that and, and thick. I mean like cause there's so many layers of skin there, it's kinda of all dried and hardened

9. Skin dryness [01-02]: When you get out it's hardening it back up but then on the slight corners it will raise up a tiny bit because of the it's drying back up so like a curling thing. When it gets fully dried up then that's when you start you start feeling the sensation of it drying up. ... That's when you're putting on your clothes or when you just move around a certain area. It ends up um, peeling off, flaking off, and something like that when it dries up fully

10. Skin [01-15]: It's, it, it's itchy and it's irritating...it just keeps, you just keep itching, just keep scratching or you irritation keep wanting to just pull the, pull the scales off and constantly keep pulling the scales off, just to like, after you pull the scales off put lotion and just try to get that rough part away, the roughness away...do I get the irritating without the itchiness? No, those come hand in hand 
Table 4 continued

\begin{tabular}{|c|c|}
\hline Item & Example quotes \\
\hline 11. Skin sensitivity & $\begin{array}{l}\text { [01-01]: ... when you have the pain it's very sensitive. Even if somebody touches you, even if } \\
\text { you get touched by the clothes, it's very sensitive in that area...I think I become sensitive, very } \\
\text { sensitive is when, sometimes I say to my wife, to put the cream on my back, which on my back } \\
\text { I could feel my back in pain right away, because the skin is so sensitive }\end{array}$ \\
\hline 12. Skin lesions & $\begin{array}{l}\text { [01-14]: Um, what happened is, it starts with a small lesion, you know, like a rough scratch on } \\
\text { your skin and it kind of becomes bigger. Again, there's no open wound whatsoever, it just } \\
\text { starts from a small dark spot and then if you don't treat it well it becomes a bigger dark spot, } \\
\text { you know, the skin }\end{array}$ \\
\hline 13. Skin thickening & $\begin{array}{l}\text { [01-04]: Yeah, I mean the scales can be like giant thick pieces of skin. You know like um, like } \\
\text { fish scales...thick because the skin is growing so fast I guess, that the fuses the skin, are you } \\
\text { know, no kidding like two or three millimeters thick, see }\end{array}$ \\
\hline 14. Sleep loss ${ }^{a}$ & $\begin{array}{l}\text { [01-07]: ...your feet are really rough or something like that and they're like pulling on the } \\
\text { sheets. (laughing) That ends up happening. And um, the um, you know I'll get up in the } \\
\text { middle of the night. I might have to moisturize it, it, it might be too dry. So you know, it does } \\
\text { wake you up when it starts to bother you }\end{array}$ \\
\hline 15. Fatigue & $\begin{array}{l}\text { [01-15]: It drains you...you don't want to do nothing all day. If somebody asks you to do } \\
\text { something, I don't feel like going out...I'm not as active, because with the medications and } \\
\text { everything, it's just, it feels like it's draining }\end{array}$ \\
\hline $\begin{array}{l}\text { 16. Feelings of } \\
\text { embarrassment }\end{array}$ & $\begin{array}{l}{[01-08]: \text {... if that starts to flare up, that's embarrassing because I have these big rosy patches, I }} \\
\text { haven't let them get to the point of flaking but they're big red rosy patches on each side of my } \\
\text { nose }\end{array}$ \\
\hline $\begin{array}{l}\text { 17. Avoid doing usual } \\
\text { activities }^{\mathrm{a}}\end{array}$ & $\begin{array}{l}\text { [01-11]: Do I, do I have to go out because I don't really feel like going out because like that, } \\
\text { you're having a little bit of bad mental day, just want to sit inside for a little longer away from } \\
\text { all that stuff }\end{array}$ \\
\hline $\begin{array}{l}\text { 18. Personal } \\
\text { relationships }^{\mathrm{a}}\end{array}$ & $\begin{array}{l}\text { [01-01]: On the worst, worst day is when my wife, when she asks me a question and I don't } \\
\text { want to answer it, I don't feel like answering it, or my son...Q: You don't feel like answering } \\
\text { their questions? A: No... Because I'm in pain, upset }\end{array}$ \\
\hline 19. Choice of clothing & $\begin{array}{l}\text { [01-08]: You don't want to, you don't, you try to cover up the spots as much that are on your } \\
\text { body. And being that it's covering the majority of every spot of my body there is really nothing } \\
\text { that I even want to show...It is on my hands, but like I said, I try to control that the most } \\
\text { since, I work and type and everything in front of customers, with my job. Um, I can't wear } \\
\text { shorts or a skirt if I wanted to, um, at this point I can't even wear, um, sandals... Because the } \\
\text { spots are on my feet }\end{array}$ \\
\hline
\end{tabular}

$A$ answer, $P$-SIM psoriasis symptoms and impacts measure, $Q$ question

a This item was ultimately removed from the final 14-item P-SIM

P-SIM item finalisation, data from week 0 $(n=163)$ and week $1(n=159)$ were used for initial quantitative analysis.

\section{Item Score Distribution}

At week 0, mean response scores on the 11-point NRS ranged from 2.2/10 (personal 
Table 5 Cognitive interview results: instructions and items

\begin{tabular}{|c|c|c|}
\hline \multirow[t]{2}{*}{ Instructions/item } & \multicolumn{2}{|l|}{ Debriefing characteristic } \\
\hline & Interpreted as intended, $n(\%)$ & Participant would not re-word, $n(\%)$ \\
\hline Instructions & $15 / 15(100.0)$ & $15 / 15(100.0)$ \\
\hline 1. Skin itching & $15 / 15(100.0)$ & $12 / 14(85.7)$ \\
\hline 2. Skin redness & $14 / 14(100.0)$ & $12 / 14(85.7)$ \\
\hline 3. Skin pain & $13 / 15(86.7)$ & $9 / 12(75.0)$ \\
\hline 4. Skin burning & $9 / 14(64.3)$ & $7 / 9(77.8)$ \\
\hline 5. Skin scaling & $9 / 15(60.0)$ & $8 / 9(88.9)$ \\
\hline 6. Skin stinging ${ }^{\mathrm{a}}$ & $10 / 15(66.7)$ & $8 / 9(88.9)$ \\
\hline 7. Skin cracking & $14 / 15(93.3)$ & $13 / 13(100.0)$ \\
\hline 8. Skin flaking ${ }^{\mathrm{a}}$ & $11 / 14(78.6)$ & $11 / 11(100.0)$ \\
\hline 9. Skin dryness & $14 / 14(100.0)$ & $14 / 14(100.0)$ \\
\hline 10. Skin irritation & $9 / 15(60.0)$ & $7 / 9(77.8)$ \\
\hline 11. Skin sensitivity & $8 / 14(57.1)$ & $6 / 8(75.0)$ \\
\hline 12. Skin lesions & $12 / 15(80.0)$ & $7 / 12(58.3)$ \\
\hline 13. Skin thickening & $14 / 14(100.0)$ & $11 / 14(78.6)$ \\
\hline 14. Sleep loss ${ }^{\mathrm{a}}$ & $14 / 15(93.3)$ & $10 / 12(83.3)$ \\
\hline 15. Fatigue & $12 / 14(85.7)$ & $8 / 10(80.0)$ \\
\hline 16. Feelings of embarrassment & $15 / 15(100.0)$ & $13 / 14(92.9)$ \\
\hline 17. Avoid doing usual activities ${ }^{\mathrm{a}}$ & $14 / 15(93.3)$ & $12 / 14(85.7)$ \\
\hline 18. Personal relationships ${ }^{a}$ & $15 / 15(100.0)$ & $11 / 15(73.3)$ \\
\hline 19. Impact on my choice of clothing & $13 / 13(100.0)$ & $10 / 12(83.3)$ \\
\hline
\end{tabular}

$P$-SIM psoriasis symptoms and impacts measure

a This item was ultimately removed from the final 14-item P-SIM

relationships and avoid doing usual activities) to 5.8/10 (skin dryness; Supplementary Table S7). Low mean response scores $(<3.0 / 10)$ were reported for skin stinging, sleep loss, fatigue, avoid doing usual activities and personal relationships items (Supplementary Table S7). At Week 1, the avoid doing usual activities item continued to have the lowest mean response score (1.8/10) and had positively skewed distribution (Supplementary Table S8).

\section{Inter-Item Correlation}

Inter-item correlations were assessed at week 0 and week 1 , to identify high correlations between items that may be indicative of overlapping concepts in the preliminary 19-item P-SIM. High Pearson's correlations were observed between skin pain and skin burning (week $0=0.84$, week $1=0.90$ ), skin pain and skin stinging (week $0=0.82$, week $1=0.92$ ), skin scaling and skin flaking (week $0=0.85$, week $1=0.94$ ), skin redness and skin lesions (week $0=0.78$, week $1=0.93$ ) and sleep loss 
Table 6 Cognitive interview results: responses

\begin{tabular}{|c|c|c|}
\hline \multirow[t]{2}{*}{ Response scale } & \multicolumn{2}{|c|}{ Debriefing characteristic } \\
\hline & $\begin{array}{l}\text { Interpreted as } \\
\text { intended, } n(\%)\end{array}$ & $\begin{array}{l}\text { Response scale matches } \\
\text { question, } n(\%)\end{array}$ \\
\hline 1. 0 (No skin itching)-10 (very severe skin itching) & $15 / 15(100.0)$ & $11 / 11(100.0)$ \\
\hline 2. 0 (No skin redness)-10 (very severe skin redness) & $15 / 15(100.0)$ & $10 / 10(100.0)$ \\
\hline 3. 0 (No skin pain) -10 (very severe skin pain) & $12 / 14(85.7)$ & $11 / 12(91.7)$ \\
\hline 4. 0 (No skin burning) -10 (very severe skin burning) & $13 / 15(86.7)$ & $4 / 5(80.0)$ \\
\hline 5. 0 (No skin scaling) -10 (very severe skin scaling) & $15 / 15(100.0)$ & $8 / 9(88.9)$ \\
\hline 6. 0 (No skin stinging) -10 (very severe skin stinging) ${ }^{a}$ & $14 / 14(100.0)$ & $8 / 8(100.0)$ \\
\hline 7. 0 (No skin cracking)-10 (very severe skin cracking) & $14 / 15(93.3)$ & $11 / 11(100.0)$ \\
\hline 8. 0 (No skin flaking)-10 (very severe skin flaking) ${ }^{\mathrm{a}}$ & $15 / 15(100.0)$ & $11 / 11(100.0)$ \\
\hline 9. 0 (No skin dryness)-10 (very severe skin dryness) & $14 / 15(93.3)$ & $11 / 11(100.0)$ \\
\hline 10. 0 (No skin irritation) -10 (very severe skin irritation) & $12 / 15(80.0)$ & $7 / 8(87.5)$ \\
\hline 11. 0 (No skin sensitivity)-10 (very severe skin sensitivity) & $14 / 14(100.0)$ & $8 / 8(100.0)$ \\
\hline 12. 0 (No skin lesions)-10 (very severe skin lesions) & $15 / 15(100.0)$ & $10 / 11(90.9)$ \\
\hline 13. 0 (No skin thickening) -10 (very severe thickening) & $15 / 15(100.0)$ & $9 / 10(90.0)$ \\
\hline $\begin{array}{l}\text { 14. } 0 \text { (No itch-related sleep loss)-10 (worst possible itch-related } \\
\text { sleep loss) }\end{array}$ & $14 / 15(93.3)$ & $11 / 11(100.0)$ \\
\hline 15. 0 (No fatigue) -10 (worst possible fatigue) & $11 / 13(84.6)$ & $7 / 8(87.5)$ \\
\hline $\begin{array}{l}\text { 16. } 0 \text { (No feelings of embarrassment)-10 (worst possible feelings of } \\
\text { embarrassment) }\end{array}$ & $15 / 15(100.0)$ & $13 / 13(100.0)$ \\
\hline $\begin{array}{l}\text { 17. } 0 \text { (No avoidance of my usual activities)-10 (completely avoided } \\
\text { doing my usual activities) })^{\mathrm{a}}\end{array}$ & $15 / 15(100.0)$ & $12 / 12(100.0)$ \\
\hline $\begin{array}{l}\text { 18. } 0 \text { (No impact on personal relationships) }-10 \text { (completely } \\
\text { impacted personal relationships) })^{a}\end{array}$ & $15 / 15(100.0)$ & $13 / 13(100.0)$ \\
\hline $\begin{array}{l}\text { 19. } 0 \text { (No impact on my choice of clothing) }-10 \text { (completely } \\
\text { impacted my choice of clothing) }\end{array}$ & $15 / 15(100.0)$ & $10 / 10(100.0)$ \\
\hline
\end{tabular}

P-SIM psoriasis symptoms and impacts measure

a This item was ultimately removed from the final 14-item P-SIM

and fatigue (week $0=0.85$, week $1=0.92$; Supplementary Tables S9 and S10). In addition, similar results were also seen with Spearman's correlations at Week 0 and Week 1 (Supplementary Tables S11 and S12).

Based on results from the item score distribution and inter-item correlation analyses, five items were removed from the preliminary 19-item P-SIM. Due to low mean response score and a positively skewed distribution, the avoid doing usual activities item was removed from the questionnaire. It was deemed that the items with the highest floor effects were not as relevant to patients and were unlikely to capture 
any improvement. Therefore, the personal relationship item was also removed because of floor effects. As a result of suggested conceptual overlap, items on skin stinging and skin flaking were also removed. The sleep loss item showed floor effects and conceptual overlap, so this item was removed because of poor results in both analyses. After the removal of these items, the final version of the P-SIM contained 14 items.

\section{DISCUSSION}

The aim of this study was to develop a PRO measure to capture patient experiences of signs, symptoms and impacts of plaque psoriasis. As such, the preliminary 19-item P-SIM was developed using concepts identified from a targeted literature review and clinical expert interviews. The preliminary 19-item P-SIM version was then tested through qualitative patient interviews to evaluate the content validity and usability of the PRO measure. The results from the patient interviews were used in conjunction with results of quantitative analyses to inform the removal of several items and produce the final 14-item P-SIM. The methods used in this study were in accordance with the Food and Drug Administration's (FDA) guidance on the development and use of new PRO instruments to support label claims $[19,20]$.

The P-SIM reports signs, symptoms and impacts of psoriasis without using any multibarreled items; concepts are assessed individually in the P-SIM, unlike some other PRO measures that combine key items, such as itch and pain. This allows patients to respond with a different level of severity for each item, providing a more accurate assessment and greater granularity to better understand the patient experience of plaque psoriasis. Accuracy and granularity were also increased in this study by using daily assessments and a 24-h recall period; this would allow early changes in symptoms to be captured, relevant in phase 3 clinical trials aiming to evaluate treatment efficacy. In addition, concepts are relevant to patients as shown during concept elicitation questioning in patient interviews.
Three items from the P-SIM (skin itch, skin pain and skin scaling) were used as secondary end points in phase 3 bimekizumab clinical trials to support efficacy and label claims (NCT03370133; NCT03410992; NCT03536884). Itch and scaling were mentioned by all patients during concept elicitation. Although pain was only mentioned by $53 \%$ of patients, it was rated as bothersome along with itch and scaling. The aim is to ensure patients' perspectives complement the "gold standard" clinician-reported outcome measures (PASI and IGA) in the evaluation of treatment benefits. Skin pain and itching are subjective concepts most accurately assessed directly by the patient. Thus, inclusion of subjective patient-reported concepts alongside the clinician-reported concepts is critical in ensuring a comprehensive assessment of psoriasis signs and symptoms. In addition, both the PASI and IGA assess skin scaling, and by including a patient-reported assessment of skin scaling, this will further ensure that the concept is holistically assessed.

Five items were removed from the preliminary 19-item P-SIM to produce the final 14-item version: avoidance of usual activities, personal relationships, sleep loss, skin stinging and skin flaking. The item assessing the impact of plaque psoriasis on personal relationships was removed because of a high floor effect and may not distinguish differences between patients because of the low scores reported by patients. However, it may be that these low baseline scores were due to patients being reluctant to report impacts on their personal relationships because of feelings of embarrassment.

Compared with the sample sizes generally used in randomised clinical trials, a small sample size was used for the patient interviews. Although this is not unusual for PRO qualitative research, it presents a limitation in the analysis and interpretation of these data. However, conceptual saturation was achieved by the 11th interview, suggesting the sample size used was appropriate to identify all signs, symptoms and impacts of plaque psoriasis experienced by patients. A further limitation of this study was that the patients recruited for interview were predominantly white and all five clinicians interviewed were white. Additionally, although 
most papers included in the literature review did not report patient ethnicity, in those that did, the majority of patients were white. Although this is typical of the general psoriasis patient population, this study and those included in the literature review do not fully capture the experience of patients with skin of colour, who are at greater risk of developing skin hyperor hypo-pigmentation [21]. Therefore, the results presented here may underemphasise the impact of hyper- or hypo-pigmentation, and the questionnaire may perform differently in a patient sample with varied skin types and tones.

Since the P-SIM aims to capture patients' experiences of key plaque psoriasis signs, symptoms and impacts, the effect of PsA on the results of the P-SIM has not been evaluated. However, PsA was reported by some psoriasis patients included in the patient interviews and phase $2 \mathrm{~b}$ study used for quantitative analyses of the P-SIM [15]. PsA is a common comorbidity of psoriasis and may impact on patients' responses to the questionnaire [2, 6]. The P-SIM may therefore not fully capture the experiences of psoriasis patients with PsA.

\section{CONCLUSIONS}

In conclusion, the P-SIM was developed to measure the signs, symptoms and impacts of plaque psoriasis from a patient perspective. This study demonstrates that the measure has good content validity. Furthermore, feedback from patient interviews shows that the instructions, items and responses included in the P-SIM are easily understandable and the device easy to use. Once further validated by full psychometric testing, the P-SIM may be a useful PRO measure alongside clinical measures in future studies assessing treatment efficacy in patients with moderate to severe plaque psoriasis.

\section{ACKNOWLEDGEMENTS}

The authors thank the patients, the investigators and their teams who took part in this study; investigators on this study were Stephen K Tyring, MD, PhD and Patricia Lee, MD, from
Center for Clinical Studies, Houston, TX. The authors acknowledge Kristina Harris, DPhil, UCB Pharma, Hong Kong, and Chad Gwaltney, PhD, Gwaltney Consulting, Westerly, Rhode Island, USA, for their contribution to this work. The authors also acknowledge Susanne Wiegratz, MSc, UCB Pharma, Monheim, Germany for publication coordination.

Funding. The literature review and patient interview study as well as the BE ABLE 1 phase 2b clinical trial (NCT02905006) were funded by UCB Pharma. The journal's Rapid Service Fee was also funded by UCB Pharma.

Authorship. All named authors meet the International Committee of Medical Journal Editors (ICMJE) criteria for authorship of this article, take responsibility for the integrity of the work as a whole, and have given their approval for this version to be published.

Authorship Contributions. Substantial contributions to study conception and design: Alice B. Gottlieb, Valerie Ciaravino, Christopher Cioffi, Luke Peterson, Richard B. Warren; substantial contributions to analysis and interpretation of the data: Alice B. Gottlieb, Valerie Ciaravino, Christopher Cioffi, Luke Peterson, Richard B. Warren; drafting the article or revising it critically for important intellectual content: Alice B. Gottlieb, Valerie Ciaravino, Christopher Cioffi, Luke Peterson, Richard B. Warren; final approval of the version of the article to be published: Alice B. Gottlieb, Valerie Ciaravino, Christopher Cioffi, Luke Peterson, Richard B. Warren.

Medical Writing and Editorial Assistance. The authors acknowledge Louise Whiteley, MSci, and Emma Phillips, PhD, from Costello Medical, UK, for medical writing and editorial assistance based on the authors' input and direction. This assistance was funded by UCB Pharma.

Disclosures. Alice B Gottlieb: Received honoraria as an advisory board member and consultant for Avotres Therapeutics, Beiersdorf, Boehringer Ingelheim, Bristol-Myers Squibb, Eli 
Lilly, Incyte, Janssen, LEO Pharma, Novartis, Sun Pharma, UCB Pharma and Xbiotech (only stock options which she has not used); received research/educational grants from Boehringer Ingelheim, Incyte, Janssen, Novartis, Sun Pharma, UCB Pharma and Xbiotech. Valerie Ciaravino, Christopher Cioffi and Luke Peterson: Employees of UCB Pharma. Richard B. Warren: Research grants and/or consulting fees from AbbVie, Almirall, Amgen, Arena, Avillion, Bristol-Myers Squibb, Boehringer Ingelheim, Celgene, Eli Lilly, Janssen, LEO Pharma, Novartis, Pfizer, Sanofi and UCB Pharma. Supported by the Manchester NIHR Biomedical Research Centre. Editor-in-Chief of this journal.

Compliance with Ethics Guidelines. All patients gave informed consent. This study and the phase $2 \mathrm{~b}$ clinical trial (BE ABLE 1: NCT02905006) used for quantitative analysis were conducted in accordance with the principles of the Declaration of Helsinki and the International Conference on Harmonization Guidance for Good Clinical Practice. Independent institutional review board and international ethics committee approvals were obtained from those listed in Supplementary Table S1, including the following central ethics committees and institutional review boards (IRB): Research Review Board Inc., Canada; Western IRB, US; Copernicus Group IRB, US; Komisja Bioetyczna przy Dolnoslaskiej Izbie Lekarskiej, Poland; Egeszsegugyi Tudomanyos Tanacs Klinikai Farmakologi ai Eti, Hungary; FN Kralovske Vinohrady, Czech Republic.

Data Availability. Data sharing from nonclinical studies is outside of UCB's data sharing policy. However, underlying data from the $\mathrm{BE}$ ABLE 1 phase 2b clinical trial (NCT02905006) reported in this manuscript may be requested by qualified researchers 6 months after product approval in the US and/or Europe, or global development is discontinued, and 18 months after trial completion. Investigators may request access to anonymised individual patient-level data and redacted trial documents which may include: analysis-ready datasets, study protocol, annotated case report form, statistical analysis plan, dataset specifications and clinical study report. Prior to use of the data, proposals need to be approved by an independent review panel at www.Vivli.org and a signed data sharing agreement will need to be executed. All documents are available in English only, for a prespecified time, typically 12 months, on a password protected portal.

P-SIM Questionnaire Copyright and Use. The P-SIM questionnaire is copyrighted by UCB Biopharma SPRL and, should you be interested in using the P-SIM, the questionnaire use is free of charge but requires explicit written permission to use from UCB Biopharma SPRL for each study. This permission will be granted if the study sponsor agrees to the conditions mentioned below (an agreement by email is sufficient).

The following conditions apply for the permission to use the P-SIM:

1. The permission to use from UCB Biopharma SPRL must be acknowledged in any publication as follows: "The P-SIM questionnaire is used by [Name of Sponsor] with the permission of the copyright holder, UCB Biopharma SPRL, S.A., Belgium".

2. UCB Biopharma SPRL should be given the opportunity to comment, from a PRO methodology perspective, on any abstracts, papers and other peer-reviewed communications resulting from the use of the P-SIM, prior to their submission.

3. Any additional linguistic adaptations must be developed, at a minimum, according to the methodological standards defined in Acquadro et al. (2004) Mapi Research Institute (Ed.) [22]. As developer of the questionnaire, UCB Biopharma SPRL must be consulted from a methodological standpoint in these adaptations.

4. A royalty-free, non-exclusive, perpetual license to use all newly-produced translations in any indication must be granted to UCB Biopharma SPRL and its affiliates worldwide.

Open Access. This article is licensed under a Creative Commons Attribution-NonCommercial 4.0 International License, which permits any non-commercial use, sharing, adaptation, distribution and reproduction in any medium 
or format, as long as you give appropriate credit to the original author(s) and the source, provide a link to the Creative Commons licence, and indicate if changes were made. The images or other third party material in this article are included in the article's Creative Commons licence, unless indicated otherwise in a credit line to the material. If material is not included in the article's Creative Commons licence and your intended use is not permitted by statutory regulation or exceeds the permitted use, you will need to obtain permission directly from the copyright holder. To view a copy of this licence, visit http://creativecommons.org/licenses/by$\mathrm{nc} / 4.0 /$.

\section{REFERENCES}

1. Parisi R, Symmons DP, Griffiths CE, Ashcroft DM. Global epidemiology of psoriasis: a systematic review of incidence and prevalence. J Invest Dermatol. 2013;133(2):377-85.

2. Griffiths CE, Barker JN. Pathogenesis and clinical features of psoriasis. Lancet. 2007;370(9583): 263-71.

3. Boehncke WH, Schön MP. Psoriasis Lancet. 2015;386(9997):983-94.

4. Kimball AB, Jacobson C, Weiss S, Vreeland MG, Wu Y. The psychosocial burden of psoriasis. Am J Clin Dermatol. 2005;6(6):383-92.

5. Rapp SR, Feldman SR, Exum ML, Fleischer AB Jr, Reboussin DM. Psoriasis causes as much disability as other major medical diseases. J Am Acad Dermatol. 1999;41(3):401-7.

6. Ritchlin CT, Colbert RA, Gladman DD. Psoriatic arthritis. N Engl J Med. 2017;376(10):957-70.

7. Koo J, Kozma C, Reinke K. The development of a disease-specific questionnaire to assess quality of life for psoriasis patients: an analysis of the reliability, validity, and responsiveness of the psoriasis quality of life questionnaire. Dermatol Psychosom. 2002;3(4):171-9.

8. Koo J, Kozma C, Menter A et al. Development of a disease specific quality of life questionnaire: the 12-item psoriasis quality of life questionnaire (PQOL-12) In: Presented at the American Academy of Dermatology, 61st Annual Meeting, March
21-26 San Francisco, California [abstract number: P606]. 2003.

9. Bushnell DM, Martin ML, McCarrier K, et al. Validation of the psoriasis symptom inventory (PSI), a patient-reported outcome measure to assess psoriasis symptom severity. J Dermatolog Treat. 2013;24(5):356-60.

10. Strober BE, Nyirady J, Mallya UG, et al. Item-level psychometric properties for a new patient-reported psoriasis symptom diary. Value Health. 2013;16(6): 1014-22.

11. Lebwohl M, Swensen AR, Nyirady J, Kim E, Gwaltney CJ, Strober BE. The psoriasis symptom diary: development and content validity of a novel patient-reported outcome instrument. Int J Dermatol. 2014;53(6):714-22.

12. Feldman SR, Mathias SD, Schenkel B, et al. Development of a patient-reported outcome questionnaire for use in adults with moderate-to-severe plaque psoriasis: the psoriasis symptoms and signs diary. J Dermatol Dermatol Surg. 2016;20(1):19-26.

13. Rentz AM, Skalicky AM, Burslem K, et al. The content validity of the PSS in patients with plaque psoriasis. J Patient Rep Outcomes. 2017;1(1):4.

14. Blauvelt A, Papp KA, Merola JF, et al. Bimekizumab for patients with moderate-to-severe plaque psoriasis: 60-week results from BE ABLE 2, a randomized, double-blinded, placebo-controlled phase $2 \mathrm{~b}$ extension study. J Am Acad Dermatol. 2020;S0190-9622(20):30980-4.

15. Papp KA, Merola JF, Gottlieb AB, et al. Dual neutralization of both interleukin 17A and interleukin $17 \mathrm{~F}$ with bimekizumab in patients with psoriasis: results from BE ABLE 1, a 12-week randomized, double-blinded, placebo-controlled phase $2 \mathrm{~b}$ trial. J Am Acad Dermatol. 2018;79(2):277-86.e10.

16. Charmaz K, Smith JA, Harre R, van Langenhove L. Rethinking methods in psychology. Grounded Theory London. UK: Sage; 1995.

17. Lasch KE, Marquis P, Vigneux M, et al. PRO development: rigorous qualitative research as the crucial foundation. Qual Life Res. 2010;19(8):1087-96.

18. Glaser B, Strauss A. The discovery of grounded theory: strategies for qualitative research. New York: Adline de Gruyter; 1967.

19. FDA. Guidance for industry: patient-reported outcome measures: use in medical product development to support labeling claims. Federal Register. 2009. 
20. FDA. Roadmap to patient-focused outcome measurement in clinical trials. Federal Register. 2014.

21. Kaufman BP, Alexis AF. Psoriasis in skin of color: insights into the epidemiology, clinical presentation, genetics, quality-of-life impact, and treatment of psoriasis in non-white racial/ethnic groups. Am J Clin Dermatol. 2018;19(3):405-23.
22. Acquadro C, Conway K, Girourdet C, Mear I. Linguistic validation manual for patient-reported outcomes (PRO) instruments. MAPI Research Trust, Lyon, France. 2004;184. ISBN: 2-9522021-0-9. 